\title{
The Concept of Death as Depicted in Fairy Tales
}

\author{
Koutsompou Violetta-Irene and Kotsopoulou Anastasia
}

\begin{abstract}
As times are changing and death is becoming increasingly a taboo matter, children's literature is exempted by a series of fatal events that happened predominantly a time ago within many stories. This article's main purpose is to analyze and demonstrate under psychological lens the concept of death in classic fairy tales such as Little Red Riding Hood, The Snow White and the Sleeping Beauty as well as in modern fairy tales like The Little Prince and The Happy Prince. As a conclusion, we can say that in a world, where death is a common fate of all and the only sure fact of life, children's books often find the words and colors to describe it. And it is a great comfort that the palette of death includes the whole spectrum of colors. Just as with life itself.
\end{abstract}

Index Terms-Childhood, culture, death, fairy tales, psychological perspectives.

\section{INTRODUCTION}

While, over time, the stories we heard as children (e.g. classic fairy tales, Aesopian fables) abounded in deaths, the event itself was degraded in two main ways: Initially, death was taking a strong moral dimension and a form of a fair punishment; the stepmother dies because she is evil. In this case, the objections relate to the enhancement of childhood anxiety, since the trend of young children to consider themselves responsible for the deaths of their loved ones is rather getting stronger e.g. "dad died because I used to upset him". On the other hand, the heroes' death in fairy tales lacks the finality of a fait accompli, since the Seven Little Goats, for example, return from the belly of the Wolf without pain and blood, with the same freedom they would return from a school trip. This feeling is successfully captured by the illustration of Kapatsoulia, when she depicts the big bad goat, a recognizable reverse version of a known fairytale, in a floral, quilt-like, friendly belly that will act as a compassionate temporary housing of the 7 Little Wolves. The same logic is also repeated today in comics, in which the heroes continue to exist, even if an entire skyscraper collapses against them or if their body is pierced by machine guns. In this case as well, however, the problematics of enhancing the incorrect views of children regarding the true nature of death returns. So, this article is basically informative about everyday issues depicted in fairy tales such as life itself, death, and the ways children can handle these events through fairy tales.

\section{DEATH IN FAIRY TALES}

As times change and death increasingly evolves into a

Manuscript received March 14, 2015; revised June 20, 2015.

The authors are with the AKMI Metropolitan College, Athens, Greece (e-mail: k_violetta120@yahoo.com). taboo, literature for children seems to be discharged from a series of fatal events that routinely occurred in the context of many old stories. One of the first examples of this particular "catharsis" is the story of Red Riding Hood which, when abandoning Perrault's version, passed from an initial phase of reversibility (the grandmother and the little girl jump out of the wolf's belly intact) in order to get to the latest, complete halt of even the temporary eating of Little Red Riding Hood and her grandmother (due to the early intervention of the hunter).

While over time, the stories the children heard (e.g. the classic fairy tales, Aesopian fables etc.) were full of deaths, this very fact was devalued in two main ways: Firstly, death gained a strong moral dimension and took the form of just punishment; the stepmother dies because she is evil. In this case, the objections add to the re-enforcement of childhood anxiety, since the tendency of small children to consider themselves responsible for the death of their loved ones is rather strengthened; e..g "Dad died because I made him unhappy", "it was my fault". On the other hand, the death of fairy tales' heroes lacks the terminal quality of a fait accompli, since the seven little goats, for example, return from the belly of the wolf without any pain or blood, with the same ease that they would return from a school trip. This feeling is successfully captured in Kapatsoulia's illustration when the big bad goat is depicted in a recognizable reversal of the known tale; a floral, quilted, friendly belly will serve as a compassionate temporary stay of the seven small wolves. (see The goat and the 7 little wolves by Rossi-Zairi, publ. Rossi). The same approach is repeated today in comics where heroes still exist, even if an entire skyscraper collapses on them or if their bodies are run through by machine guns. And in this case, however, the issue of strengthening the false views of children regarding the true nature of death returns. However, although in modern illustrated children's books, deaths are rare, if not 'endangered' facts, a series of new books makes it a central theme, focusing on the painful period before and immediately after the death of loved ones. Acting more as a starting point for a discussion between children and adults for an issue that, despite the pain it brings, is common fate for everyone; in that context, all similar books seek to bring children into contact with facts already known to them or likely to experience [1]-[5]. Because if you cannot guarantee that children will not face the death of a beloved person in their lives, it makes no sense to protect them unilaterally from a painful experience in their books! For example, the illustrated children's book that includes various themes, such as the choice of heroes children or the use of generic terms (eg. grandfather instead of his own name) emphasizes the community of a universal experience since death is presented as everyone's business. Indeed, there are also those very few cases where the narrator makes a straight attempt for an active identification with the 
dying person. The book which chronicles the adventures of a small fish until it reaches the shelves of a groceries store in a box of sardines, begins with the provocative "You would definitely like to become salted fish", while the equally shocking 'Get ready, you will soo die ... " from "Would you like to be a mummy in Egypt?"; a knowledge book with an obvious subject and a idiosyncratic narrative style, at times were met with the reactions of adult and juvenile readers [6], [7].

Although these books are a small and most often an unwelcome minority, the majority of the illustrations, while seeking to first familiarize readers with the issue of death, are also adopting numerous verbal and pictorial tricks so as to achieve a form of distancing and positive signaling of an event which, by its nature, ensures only a small margin for amelioration.

\section{THE COLOUR OF DEATH}

If someone asked the children to describe the color of death, nine out of ten would refer to dark and gloomy shades-with black colour dominating. Inherited cultural memories and modern burial practices dress the children's anthropomorphic construction of Death with jet-black clothes, identifying the representation of its shape with the iconographic rendering of the Reaper (Charon in Greek) in many children's books (see Digenis Akritas, ill. Anta \& Svetlin, ed. Papadopoulos). In the books, though, where the topic of loss and bereavement is tackled, possibly in a gesture of de-escalation of the tension, black is abandoned, as the illustrator adds to his the palette the entire color spectrum. Some authors choose bold, cheerful colors who, in combination with well-designed, rotund figures seek to exorcise with a visual euphemism the pain of death (see the Old Pig). Others prefer brown, earth tones, perhaps with clear connotations of burial customs and religious views of the return to Mother Earth (Melenios and his grandfather who passed away), while others resort to soft colors, creating what we might call a "mood book" where pain is not proclaimed but merely suggested [8]. When even the faint discretion of colors is accompanied by the use of watercolor, the images in the book, damp from the humidity of watercolors, refer directly to a sense of wetness created by tears shed (see The Wall). absence of colour and the presence of a harsh bright white (see Annie and the Old One, where the initially black and white drawing is marginally accompanied by the most discreet presence of soft colors).

In the same philosophy where softening any painful spikes with euphemistic tendencies also runs -parallel to the illustration- the narration of the text, since they often chose for death a number of poetic or metaphorical descriptions which, while they carry the same weight of information, they differ significantly in their emotional and experiential colouring [8]. As much as many disagreements are expressed with the number of lenient, softer expressions used to indicate death, in that they may not only cause confusion (e.g. the "long journey", the negation of the inaction of death, experiencing a life somewhere else) and unnecessary fears in children (separation anxiety or sleep denial), many a time children's books are overwhelmed by verbs such as he "left" or he is "sleeping", as they struggle with a verbal exorcism, in order to attack the absoluteness and to ram the irreversibility of a fait accompli situation [9].

In modern books dealing with death, a way of smoothing an intrinsically intolerable experience regards the selection of heroes who, in fictional contexts, will experience the inevitable fate. Beginning with the withering of plants, death occurs as a metonymy like the damage of the plant (e.g. The leave that did not want to fall), the brief period of prosperity and flowering of the trees and flowers evoking the eternal cycle of life that deterministically passes from wear into rejuvenation, and from decline into regeneration. The selection of photographs for the illustration of the book The Fall of the leave called Freddy in conjunction with the subtitle A Story of Life for All Ages and the odd addition of the word The Beginning not on the first page but on the last one, strongly emphasizes the hopeful message describing a grim event with positive terms.

Following that, death occurs in the animal kingdom, sometimes taking the form of loss of a beloved pet (proposed responses on this loss, on the website: http://www.amorak.net/ReviewsPetLossChildren.html) and sometimes heroes- anthropomorphic animals who, as the protagonists of stories experience something painful. The Goodbye Little Mouse book describes the pain of the child before the death of his beloved hamster, while several animals who live and move in human societies (e.g. Together Forever) are facing losses of beloved friends or relatives.

Moreover, the tendency of such books for the presentation of the so-called 'legitimate' deaths is particularly evident in an attempt to defuse the psychological stress. In the field of the illustrated children's books deaths are calm and are usually for the very elderly or for those who play a secondary role in the lives of children, while they are often viewed as the natural ending of an acclaimed course of someone's life [10]. Most often the death of a grandfather or grandmother is presented; these are people who, while maintaining valuable relationships especially with their young grandchildren, they have not been charged with the primary responsibility of raising them. On the other hand, all these senseless deaths that hurt and enrage us are usually suppressed, including violent deaths, the unnecessary carnage of war (Hiroshima 1945), the loss of parents or the deaths of young children (between the exceptions is The Little Girl With the Matches).

As always, however, it remains unclear how a particular child will react to the idea of death, so very often illustrated books for children choose to speak vaguely about it with the help of a deliberate ambiguity; they aim at softening the impression giving to the children who wish so the denial of death. Serving a concept of (super?) protection, many illustrated books for children with a range of textual and pictorial tricks, manage the impossible: to prevent the inevitable, since the book leaves it to the reader to reach to the assumption (or not) of death.

Many times, the event occurs implicitly since an 'open' end calls for a pluralistic reading that reaches the conflicting interpretation, since other audiences may include in the text the version of death and others to read it in a shiny happy end. Sometimes, the possibility of the denial of death as a fait complit as it occurs at the end of a story, is given by creating a dimension between the two modalities that support the 
illustrated children's book: text and image.

As the textual narrative does not coincide with the illustration, the ambiguity of the text "about what eventually came to pass, is he dead or not?" is contrasted by the defining purity of the illustrations through colorful pathways leading to a version of unhappy endings. When the text cannot find the words to announce the absoluteness of death, the illustration discovers the colours to describe it; as the colorful celebration of joyful shapes of the illustration speaks less painfully than the mourning signs scattered on a white background devoid of a textual statement [11].

In the book The Grandfather flies, while the text could narrate a (fictional) journey of a grandfather and a grandson that lasts one full day and ends with the sunset, the answer for all the dreamscapes visited by the heroes lies within the room as depicted in the original first two-pages of the story [12]. With bold elements of self-interpictuality since the pictorial narrative firmly supports visually the concept of the book, the successive sets of all their visits are merely imaginary flights to different corners of the same room; the idyllic village resides in the painting adorning the wall opposite the bed, the strawberries field starts with a full bowl on the table, the meeting with the birds begins with a closed book draped over the stool, and the garden with the blue bells is relief detail on a vase.

The pictorial view of a journey constricted in the boundaries of the room also suggests the concept of the critical state of health in the elderly grandfather, which inevitably leads to the twilight of his life, which is alluded by the illustration. The constant repetition of the figure of the grandfather who travels everywhere with closed eyelids, is strengthened in the last picture where the closed eyes will complement the hands crossed on the chest and a series of flowers could possible reflect burial customs. The windowexit to the dream world returns on the last page, but this time, unlike the original one, it is now closed- marking also the 'closure' of the cycle of life [13]. The final two-page spread is the only one devoid of human presence in the text -which is present as an absence of dialogue between the two heroeswhile rife with elements/connotations of the separation of the soul from the body: the singing bird is hopelessly pitch black, the pulled curtain forms an intangible nebula, the yellow butterfly refers to visual representations of human souls, while all the illustrating allusions culminate in the faint shadow of an angel which does not correspond to any object of the material world [14].

Furthermore, even when the textual narrative is complete, leaving only a hint of death, the illustrational narrative continues after the end of the story, as it goes beyond the limits usually taken by a book, overflowing until the final inside page (wallpaper). This is not the usual cliché of the recurrence of the original; the plot progresses, the situations are clarified, the answers are finalized. The image of a little boy climbed onto a chair greeting his grandfather with eyes closed and pajamas', riding a star, transforms the temporality of sleep into the eternity of death, while it also echoes ancient myths of souls ascending to heaven and becoming star-protectors of their loved ones.

On the other hand, sometimes the concept of death is supported by data structure. If we should define an expected structural shape plot, we would say that the story usually goes in a progressive escalation until the end of the book where the death of the hero takes place. Since the end of the process of reading often coincides with the end of the life of a literary hero, the symbolic function of reading as a life-giving force in a series of fairytales heroes is metaphorically stronger; they activate their existence every time the individual reader opens the book and invites them to life for as long as reading continues and until the termination of the reading; then they plunge again into a new, latent waiting period [13]. Each story heading to the final outcome suggests the meaning of the beginning, the peak and the end; each end always seems to be a symbolic death.

But when the book does not focus on the same departure of a hero from life but focuses on the management of mourning, death occurs early, and the escalation of tension that culminates in the heartbreaking loss finds space to move towards its catalysis, since the new reality is established and any impaired balance is restored. The structural shape of the plot starts from a position of equilibrium, culminating with a dramatic intensity of suffering and ends with the de-escalation introduced by the new situation and the transcendence of the experienced pain.

If the text puts forward the idea that life is an eternal course that never ends, as the area is occupied by the sweetness of favourite absent people, who, as psychological presences from then on guarantee the continuity between the before and the after, very often the pictorial narrative takes the form of a circle; the first and the last page are occupied by twin images, eliminating the feelings of endings and interceptions and presenting the idea of continuity and balance [15]. With a strong similarity between the initial and the final page of the book-that are never quite the same- life, having experienced loss, regains its old pace, taking advantage of a presence that has now ceased to exist.

Detecting similar narrative elements in the sweetest of books, Melenios and the grandfather who passed away, the grandfather and grandson's experienced daily routine is described with the initial narrative (the text refers once to what happens for $x$ times) of the first double page spreads that establishes a valuable fixed point firmly in the life of the small child: "Every Friday, Melenios, the little bear, went to see his grandfather [16]. 'How is my favourite teddy bear?' was his grandfather always asking." As this is abandoned, the idea of a threatening possibility is suggested, and the narration as unique (the text mentions once that which happens once) is going towards its peak that includes the death of the grandfather and the family experiencing the pain for the loss of the deceased. In moments of dramatic intensity, images react with a substantial reduction of the angle, replacing the long shots with close-ups and contrasting in the broad horizon of a scene the suffocating dominance of an increasingly intensive detail.

While the book draws to its end, resulting in the image without words of the last inside page (wallpaper), which is a variant of the original one. The story ends just as it began; the little teddy bear contemplating the world from the wooden structure of the tree. The garden, the birds, the plants of the original image are repeated almost unchanged [17]. The dramatic change is only the second person; the place 
grandfather is now occupied by the mother literally (the platform of the tree now becomes a well-built wooden house) and it metaphorically build the new reality of this small hero, who still seems - indicative is the posture of his body, as he is standing still quietly as opposed to the birds, which are significantly reduced the second time - to mourn for a recent, painful loss.

The mother in a symbolic gesture adds colour to his life and the light blue hue comes to replace the sweltering shades of brown - which, occupies the area of the background in the images of death and mourning — now it functions as a future promise of life and hope.

\section{CONCLUSION}

In a world where death is the common fate of all and the only certain fact of life, children's books often find the words and colours to describe it. It is so comforting that the palette of death includes the whole range of colours. Just the way it happens in life...As Hans Christian Andersen puts it: "Everything you look at can become a fairy tale and you can get a story from everything you touch".

\section{REFERENCES}

[1] C. E. Cornett and C. F. Cornett, Bibliotherapy: The Right Book at the Right Time, Bloomington, IN: Phi Delta Kappa Educational Foundation, 1980.

[2] E. H. Jones, Bibliotherapy of Bereaved Children, London: J. Kingley, 2001.

[3] H. M. Carty and L. Chalmers, "Bibliotherapy: Intervention and prevention," Teaching Exceptional Children, vol. 29, no. 6, pp. 12-13, 16, 1997.

[4] K. A. Mohr, "Metamessages and problem-solving perspectives in children's literature," Reading Horizons, vol. 33, no. 4, pp. 341-346, 1993.

[5] D. T. Ouzts, "The emergence of bibliotherapy as a discipline," Reading Horizons, vol. 31, no. 3, pp. 199-206, 1991.

[6] J. Pardeck, "Bibliotherapy: An innovative approach for helping children," Early Child Development and Care, vol. 110, pp. 83-88, 1995.

[7] R. J. Riordan and S.W. Linda, "Bibliotherapy: Does it work?" Journal of Counseling and Development, vol. 67, no. 9, 1989.

[8] T. J. Riecken and M. R. Miller, "Introducing children to problem solving and decision making by using children's literature," Social Studies, vol. 81, no. 2, pp. 59-64, 1990.

[9] A. G. Smith, "Reading guidance: Death and grief," Journal of Poetry Therapy, vol. 3, no. 1, pp. 23-28, 1989

[10] D. Sridhar and S. Vaughn, "Bibliotherapy for all: Enhancing reading comprehension, self-concept, and behavior," Teaching Exceptional Children, vol. 33, no. 2, pp. 74-82, 2000.

[11] J. Todahl, T. E. Smith, M. Barnes, and M. G. A. Pereira, "Bibliotherapy and perceptions of death by young children," Journal-of-Poetry-Therapy, vol. 12, no. 2, pp. 95-107, 1998.

[12] E. A. Grollman, Talking about Death, Boston: Beacon Press, 1990.

[13] M. Herbert, Children: Grief and Loss, Greek Letters Publishing, 2004.

[14] E. A. Grollman, Explaining Death to Children, Boston: Beacon Press, 1967.

[15] J. W. James, R. Friedman, and M. Leslie Landon, When Children Grieve: For Adults to Help Children Deal with Death, Divorce, Pet
Loss, Moving, and Other Losses, London: HarperCollins Publishing, 2001.

[16] E. Kubler-Ross, On Children and Death, New York: Touchstone, 1997.

[17] I. Smith, "Preschool children 'play' out their grief," Death Studies, vol. 15, pp. 169-176, 1991

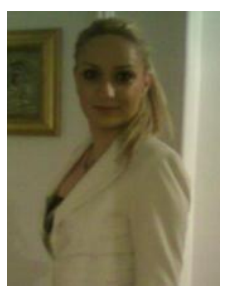

Koutsompou Violetta-Irene holds a bachelor degree in English language/literature and psychology from the State University of New York, USA, 2007, holds a master's degree in English and comparative literature from the University of Indianapolis, USA, 2009. She has an accredited certificate in TEFL in 2007, she received a professional diploma in counseling psychology from City Unity College, Athens, Greece, 2013 and a master of science degree in psychology from the University of East London, UK. She has attended seminars and specializes in psychoanalysis and Jungian psychology at the Carl Gustav Jung Institute, in Zurich. Ms. Koutsompou has taught as an invited lecturer in colleges in Greece where she presented her thoughts and theory about children's literature and development and loss in every aspect of life. Her areas of interest and concentration are psychology of child development, children's literature and its impact on the cognitive and emotional development, depression, grief and loss, second language acquisition, postmodern literature, women's psychology and writings, book editing and writing. She has worked in private language institutions in Greece since 2005; she was interested and worked with children with special learning difficulties such as dyslexia, as well as with children with behavioral problems in the language classroom. She has presented her work in many conferences in Greece and abroad and in 2013 she was awarded a Certificate of Excellence for her research in postnatal depression from the committee of the $2^{\text {nd }}$ psychology conference of City Unity College in Greece. She is a graduate member of the British Psychological Society, an Affiliate International member of the American Psychological Association, member of the TESOL Greece, of the IRED, etc.

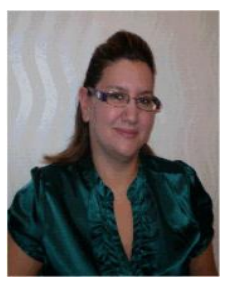

Anastasia Kotsopoulou received her $\mathrm{PhD}$ degree in education and psychology from the Institute of Education-University of London in 2002. She is a programme leader in education and psychology at AKMI Metropolitan College in Greece. She has worked in many private colleges in Greece both as the head of the Psychology Departments and as a lecturer of psychology and education. She had been the head of the Psychology Department of City Unity College where she organized three psychology conferences with great success; she was also the founder and supervisor of the Counseling Center of City Unity College in Athens. Her experience includes working with children with autism (Lovaas method), children and adults with behavioral problems in the counseling center at the University of London, but also in other counseling and psychological centers providing psychological support to abused women, children, and people with addictions. Her primary research interests focus on the use of background music that accompanies the study of students. Her research interests include the use of music in various aspects of our lives, for example at work, driving, shopping malls, supermarkets, etc. She has also studied the process of mourning and the effects of losses in everyday life. She is the owner and headmaster of "Synchronous Support Center" that specializes in providing individual and group sessions for adolescents and adults, in particular on issues of self-esteem, behavioral problems, panic attacks, anxiety, depression, divorce, grief and loss. She is a chartered fellow of the British Psychological Society since 1997. She has also trained in Cognitive Behavioral Therapy, REBT, psychodynamic psychotherapy and art therapies. In 2011 she has been awarded the title of Associate Fellow for her contribution in the field of Psychology. 